\title{
La influencia melancólica de los poetas prerrománticos ingleses en Francia
}

\section{(The melancholic influence of English pre-Romantic poets in France)}

Soledad Díaz ALARcón

(Universidad de Córdoba)

Fecha de recepción: 10 de mayo de 2010

Fecha de aceptación: 30 de mayo de 2010

Resumen: El presente trabajo pone de manifiesto la relevancia de la epístola y la heroida en la literatura francesa del siglo XVIII, en gran parte debido a la influencia de insignes poetas ingleses como Alexander Pope, quien tomando como tema para su composición poética la legendaria historia de Eloísa y Abelardo, supo encumbrar este drama mediante la maestría de elementos clave como la melancolía y el lirismo. La traducción al francés de esta obra correrá a cargo de autores como Aimé Ambroise Joseph Feutry, gran conocedor de la literatura inglesa del siglo XVIII y Charles Pierre Colardeau, creador del término "héroïde". En este estudio realizamos un análisis de las traducciones francesas y aportamos nuestra traducción al español.

Palabras clave: Correspondencia Eloísa y Abelardo, Pope, heroida, traducción

\begin{abstract}
The present paper highlights the relevance of the epistle and the "héroïde" in French literature during the 18th Century, this is largely due to the influence of notable English poets such as Alexander Pope, who knew to exalt this drama using key elements like melancholy and lyricism with real skill and taking the legendary story of Eloise and Abelard as a topic for his poetic composition. The translation into the French language was done by authors such as Aimé Ambroise Joseph Feutry, a great expert of the 18th Century English literature and Charles Pierre Colardeau, who created the word "héroïde". In this paper we analyse the French translations and contribute with our translation into Spanish.
\end{abstract}

Key Words: Eloise and Abelard correspondence, Pope, Heroide, Translation

\section{INTRODUCCIÓN}

Es algo ya comúnmente aceptado que la literatura del siglo XVIII muestra evidentes rasgos de lo que más tarde la crítica literaria calificaría como romanticismo. Los encontramos en la prosa de Jean-Jacques Rousseau, en la búsqueda de la felicidad inalcanzable de l'abbé Prévost, en las tentativas teatrales imitadas de los ingleses, en la introducción en 
Francia de Ossian, en la actualización del género "trobadour" por parte de los eruditos, en la búsqueda del inaccesible Edén de Bernardin de SaintPierre, en la contemplación de las ruinas, o en las miradas a Grecia y a Roma. El género poético está bien nutrido de estos caracteres que podemos descubrir en André Chénier o en poetas académicos como Thomas y Delille, que dejan entrever las posibilidades de un canto interior y nuevos modos de ver y de sentir.

Este sentimiento de melancolía está presente en la epístola y en la heroida. En cuanto a la primera, se trata de una carta o discurso en verso dirigida a un destinatario. Horacio fue el inventor de un género que luego adoptará infinidad de tonos: Clément Marot lo adoptó para versificar en 'tono de broma'; Boileau para hablar de moral, de crítica, de literatura; Voltaire para tratar temas filosóficos; Bernis para dirigirse a la pereza, etc. En la década de 1760 se pone de moda en Francia un nuevo tipo de "lettre en vers", "épître héroïque", o "élégie" que conocemos como héroïde. La gran novedad que aportaba era la expresión de pasiones y sentimientos de manera subjetiva y sincera por unos personajes conocidos que escribían en primera persona y bajo la forma convenida de la carta. L'héroïde es en cierto modo una especie de tragedia bajo forma de epístola, ya que no es en absoluto necesario que la heroida esté sustentada por personajes célebres, ni que por el hecho de presentarse con estructura de epístola merezca este título. Lo que realmente constituye a la heroida es la naturaleza del tema, que ha de ser grave, triste, mezclar elementos de la epopeya y de la elegía. La acción dramática está en el pensamiento; el relato sustituye al diálogo y se debe apelar a la imaginación del lector para que éste pueda reconstruir el drama del que sólo se le ofrece una imagen. Asimismo se han de presentar a los diversos personajes mediante las impresiones de uno solo, de este modo, el poeta debe seleccionar aquel personaje más destacado para concentrar en él todo el interés y las consecuencias de la acción.

Por otra parte "l'héroïde" es un género de composición severa que exige un gran ingenio por parte del creador y grandes dotes de maestría estilística, elementos que se oponen por necesidad a la mediocridad. Este hecho supone que el número de heroidas conservadas en la literatura francesa sea escaso: las cartas de Eloísa y Abelardo ofrecieron a Beauchamps, Colardeau y Dorat el tema de varias composiciones; Barthe también se inspiró en este drama en su Lettre de l'abbé de Rancé o Gilbert con L'épître de Didon à Énée. La nueva variedad poética gozó de un éxito fulminante. Posteriormente se transformó y decayó; y finalmente desapareció del panorama literario antes de que llegasen los nuevos tiempos de la Revolución. La heroida, en el siglo XVIII, adquiere la forma de epístola y el tono de la elegía, muy cercano al modelo de Ovidio, creador y 
maestro del género. Dicho autor compuso epístolas en versos elegíacos con el nombre de algunas heroínas célebres (Penélope, Medea, Fedra, Elena...) que escriben a su amante, a su esposo ausente o infiel. Sería un género destinado a la "poésie du sentiment", término frecuentemente empleado para la poesía que expresaba la sensibilidad, frente a la puramente "d'images", "d'esprit" o "d'idées". Ovidio se constituye así en una referencia constante como modelo de expresión de sentimientos, tanto para los temas amorosos como para transcenderlos.

La notabilidad del filósofo Abelardo y la historia de su trágica historia de amor con Eloísa, constituyó para los contemporáneos del siglo XII motivo de gran interés, que se expandió a los siglos siguientes: en el XIII, Jean de Meung recuerda los dos amantes en el Roman de la Rose ${ }^{1}$ y traduce algunas de sus cartas; en el siglo XIV Petrarca anotó un códice de las Epistolae $^{2}$ con reflexiones personales. En el siglo XV Francois Villon, en La ballade des dames (1462) recuerda la "très sage Héloïse"3. A primeros del siglo XVII se publican las Epistolae en una compilación de algunas de las obras filosóficas de Abelardo ${ }^{4}$, pero es a final de siglo cuando se gesta una tradición literaria sobre la historia de amor de estos insignes personajes que supera la realidad histórica: el modelo latino se complica con la introducción de episodios imaginarios y divagaciones galantes dulcificadas de ligera sensualidad, elementos más propios del gusto de la época ${ }^{5}$. Pierre-François Godard de Beauchamps se inspiró en estas versiones libres para su creación poética en alejandrinos, publicando en 1717 la primera carta de Eloísa y la respuesta de Abelardo. Posteriormente, en 1721, en una nueva edición, añadió una segunda carta de Eloísa ${ }^{6}$. Sin embargo, el autor que sin

\footnotetext{
${ }^{1}$ Jean de Meung, Roman de la Rose, éd. E. Lauglois, Paris, 1914-1925, 5 vols., III, vv. 87598832.

${ }^{2}$ Códice. Ms. 2923 (actualmente conservado en la Bibliothèque National de Paris).

3 "Ou est la tres Heloys pour qui fut chastré et puis moyne

Pierre Esbaillart a Saint-Denis..."

(“Ballade des Dames du temps jadis", en F. VILLON, CEuvres, ed. L. Thasne, Paris, I, p. 189). ${ }^{4}$ Petri Abaelardi, Sancti Gildasii in Britannia abbatis, et Heloissae coniugis eius, quae postmodum prima coenobii Paraclitensis abbatissa fuit, opera nunc primum ex mms. codd. eruta et in lucem edita, studio ac diligentia Andreae Quercetani Turonensis (André Duchesne), Paris, 1616 , en $4^{\circ}$, sumptibus Nicolai Buon.

${ }^{5}$ Mencionamos algunas de ellas: Histoire d'Hélö̈se et d'Abelard, La Haye, 1687 (reed. 1693, 1695, 1697); Lettre d'Héloïse à Abailard, reponse d'Abailard à Héloïse, Tours, 1695; Idem, Cologne, (1696); Le Philosophe amoureux, histoire galante contenant une Dissertation curieuse sur la vie de Pierre Abaillard et celle d'Héloyse avec les intrigues amoureuses des mêmes personnes auxquelles on a joint plusieurs lettres d'Héloyse à Abaillard, et les Reponses du même à cette Belle, Au Paraclet, 1696 (numerosas reediciones).

6 Les Lettres d'Héloïse et d'Abailard, mises en vers françois par le sieur P. F. G. DE BEAUCHAMPS, Paris, J. Estienne, 1714.
} 
duda creó una obra genial, sugestiva, capaz de imponerse como modelo de uno de los temas más interesantes de la poesía europea del siglo XVIII, fue el inglés Alexander Pope, que publicó en 1717 su epístola Eloisa to Abelard $^{7}$, donde canta el amor entre los célebres personajes a través de palabras de la propia Eloísa, que se consume de amor y se atormenta por el fatídico destino que le ha sido impuesto al apartarla de su amado. Esta obra, compuesta en pareados, evidencia un elegante estilo clásico y adopta una filosofía rompedora e inusual que no cabe en modo alguno en los cánones medievales, como lo muestra la negación del matrimonio por parte de Eloísa, la reivindicación de su derecho a amar, su repudia al sacrificio realizado por ambos amantes o su falta de resignación. Elementos que vendrán reforzados por la atmósfera opresiva descrita por Pope: la noche, la oscuridad de un espacio restrictivo, amurallado, envuelto de frías esculturas que decoran las grises tumbas.

En Francia, la mayor difusión del tema poético del amor infeliz de Eloísa y Abelardo no se debe al texto inglés de Pope sino de sus traducciones francesas. Las primeras versiones en francés de la heroida de Pope fueron las de Aimé Ambroise Joseph Feutry (1751), en verso, y las versiones en prosa de Figuet du Bocage (1751) y del abate Coyer (1757). Las composiciones poéticas de Feutry destacaban más por su correcta versificación que por la "veine inspiratrice", sin embargo tradujo con talento varias obras de autores ingleses -considerados por nuestro autor verdaderos modelos a seguir- tales como Thomson, Pope y Young. Su fúnebre musa, que aspira a lo sublime, muestra movimientos bastante elocuentes, pero su expresión no es ni simple ni segura. No obstante la traducción de mayor éxito fue la Lettre d'Hélö̈se à Abailard, traducción libre de Pope realizada por Charles Pierre Colardeau. Obra en la que se aprecia una adaptación de la temática y la expresión a los gustos franceses de la época. Los mejores poemas de Colardeau -la imitación de la Lettre d'Héloïse à Abailard de Pope, y la traducción de las dos primeras Nuits de Young- dan claro testimonio de la sensibilidad prerromántica del siglo XVIII.

El éxito de público condujo a la proliferación de creaciones, a las más vivas discusiones en el mundo de la literatura y a la inevitable desconfianza de los críticos. Al mismo tiempo que se afanaban en escribir según la nueva moda, en buscar nuevos personajes, situaciones y temas, procuraban definir el nuevo género y buscarle antepasados ilustres siguiendo las exigencias de una preceptiva literaria cuyo yugo aún estaba vigente. El mismo Colardeau confirmó su éxito con una Lettre d'Armide à Reynaud, al tiempo que Dorat, Chamfort, Blin de Saimmore, La Harpe y otros menos

\footnotetext{
7 The Works of Mr. ALEXANDER POPE, printed by W. Bowyer for B. Lintot. London, 1717, I (págs. 413 y sigs).
} 
conocidos daban a la imprenta otras cartas de amantes abandonadas (Calypso à Télémaque; Octavie, soeur d'Auguste, à Antoine; Gabrielle d'Estrées à Henri IV...), respuestas de Abailard a Héloïse (las de Dorat o Erbigny), e incluso exploraban territorios novedosos como hacer hablar a Sócrates, Catón o Moctexuma. No obstante, estas composiciones quedaron superadas por el romanticismo triunfante, por lo que ni se reeditaron ni pasaron a la historia literaria.

Pero ¿cuál es la temática tratada en el texto de Pope? Ni más ni menos que la historia de amor entre Eloísa y Abelardo que comienza cuando Fulberto, canónigo de la Catedral de París, quien conoció a Abelardo en 1115, le confía la educación de Eloísa, su sobrina. La pasión surge inmediatamente entre ambos y durante un tiempo mantienen su relación en secreto. Sin embargo, el escándalo estalla al saberse que Eloísa espera un hijo de Abelardo. De este modo, nuestro protagonista secuestra a Eloísa y la lleva a casa de su hermana en Le Pallet. Pero Fulberto exige el matrimonio (no sin la reticencia de Eloísa), que acaba celebrándose en secreto y difunde la noticia del acontecimiento. La publicación de esta nueva, molesta a Abelardo y envía a Eloísa al monasterio de Argenteuil. La reacción de Fulberto no se hace esperar, pues sintiéndose engañado, decide castigar de modo ejemplarizante la conducta de Abelardo y ordena que sea maltratado y castrado. Abelardo, humillado, se esconde durante un tiempo en Saint-Denis como monje, y recluye a Eloísa en el monasterio de Argenteuil. Ya en el convento, llega a manos de Eloísa una carta en la cual Abelardo, para confortar a un amigo infeliz, le narraba sus propias desgracias (Historia calamitatum Abaelardi). La lectura de esta carta volvió a despertar el sentimiento amoroso -nunca sosegado del todo- de Eloísa. Entonces envió una carta a Abelardo, expresando a su vez sus propias penas y tormentos: se inicia así un extenso intercambio epistolar que Pope va a poner de moda en Inglaterra y, por una curiosa paradoja que se da a menudo en la literatura europea, vuelve a Francia de la mano de algunos escritores del XVIII; veamos el resumen de Feutry del argumento de la composición que va a traducir:

Abelard et Héloïse vivoient au douzième siècle; les charmes de leur figure et de leur esprit les ont rendus célèbres, et l'historie de leurs amours infortunés nous arrache encore des larmes. Après un enchaînement de malheurs, ils se retirèrent chacun dans un couvent, ou ils consacrèrent le reste de leurs jours à la pénitence. Long-temps après cette séparation, une lettre qu'Abélard écrivit à un de ses amis tomba entre les mains d'Héloïse; cet événement réveilla toute sa tendresse, et donna lieu à ces lettres fameuses d'où l'on a tiré le 
Poème suivant. On y a peint les combats de la nature, de la grace, de la passion et de la vertu 8

\section{TEXTOS Y TRADUCCIONES}

En este apartado queremos presentar las dos versiones en francés de la composición de Alexander Pope, realizadas por Feutry (1751) y Colardeau (1758) y nuestra traducción al español. En la época en que ambos autores deciden versionar la obra del autor inglés, el drama de Abelardo y Eloísa era sobradamente conocido, al igual que la obra de Pope, no obstante ninguno de los dos la siguió fielmente. La obra de Feutry se inicia con el siguiente "Avis":

Voici une édition nouvelle, de la traduction d'un des plus beaux morceaux de Poésie du célèbre M. Pope. Ce sujet, quoiqu'usé et rebattu, devient nouveau par la façon dont il l'a traité: on y retrouve par tout le Poète Anglais, ce feu, ces images, et ces traits qui le caractérisent. J'avais moins prétendu faire parler Héloïse que Pope; je pouvais puiser aux mêmes sources que cet illustre Auteur: mais je voulais tenter, sans être froid ni languissant, de rendre l'original du tableau de ce grand poète. Si dans cette Épître on découvrait des teintes de son coloris, et quelques traits de la manière de peindre, mon but alors serait rempli. ${ }^{9}(.$.

${ }^{8}$ Épître d'Helö̈se à Abelard. Traduite de M. Pope et mise en vers par M. Feutry. (1258) [En línea] <http://gallica.bnf.fr/ark:/12148/bpt6k109237z> (p.4). Consulta realizada el 5 de mayo de 2010

Argumento que traducimos a continuación:

En el siglo XII vivieron Abelardo y Eloísa. Los encantos de su rostro y de su espíritu los hicieron célebres y la historia de su desafortunado amor aún nos hace llorar. Tras una sucesión de infortunios, cada uno de ellos se retira a un convento donde consagraron el resto de su existencia a la penitencia. Mucho tiempo después de su separación, una carta que Abelardo escribió a uno de sus amigos cayó en manos de Eloísa, este hecho despertó en ella una gran ternura y dio lugar a sus afamadas cartas de las que hemos extraído el siguiente poema. En él hemos reflejado los conflictos de la naturaleza y de la gracia, de la pasión y de la virtud.

${ }^{9}$ Cita que traducimos de este modo:

Presentamos aquí una nueva edición de la traducción de uno de los pasajes más hermosos de la poesía del célebre autor Alexander Pope. El tema, aunque haya sido muy usado y trillado, adquiere novedad por la forma de tratarlo: en todo el texto del poeta inglés encontramos ese fuego, esas imágenes y esos rasgos que lo caracterizan. Mi intención no es tanto hacer hablar a Eloísa como pretende Pope y podía haber bebido de las mismas fuentes que este ilustre autor: sin embargo he querido intentar, sin caer en la frialdad ni en la languidez, impregnar de originalidad el cuadro de este gran poeta. Si en esta epístola se descubren tintes de su colorido, y ciertos rasgos de su manera de pintar, habré alcanzado mi objetivo. 
En el caso de Colardeau, en lugar de reproducir la languidez de la epístola original, quiso inmortalizar el testimonio de los amores de Abelardo y Eloísa, su espíritu, su erudición, su gusto, sus debilidades y su penitencia, recreando su obra con una gran dosis de sensibilidad y melancolía. En primer lugar presentaremos y traduciremos la versión de Feutry:

Dans ce sombre désert, solitude tranquille,

Séjour de l'innocence, et des vertus l'asile,

Où mon âme et mes yeux vers le Ciel élancés,

Ne peuvent nuit et jour le contempler assez,

Qui peut venir troubler ma retraite profonde?

Loin des plaisirs bruyants et des erreurs du monde;

Quel souvenir rallume un feu séditieux?

Mon cœur veut-il franchir l'enceinte de ces lieux?

Dans ce moment cruel, me connais-je moi-même?

Hélas! j'aime toujours... c'est Abélard que j'aime,

La trop faible Héloïse adore encore ses traits.

Nom redoutable et cher... que vous m'offrez d'attraits!

Ne les prononçons point: ma voix est consacrée

A célébrer de Dieu la Majesté sacrée;

Cachons-le dans mon cœur, qu'il y soit avec lui,

Que leurs traits confondus se mêlent aujourd'hui.

Ne l'écris point, ma main; ... mais ce nom plein de charmes

Déjà s'offre à mes yeux... Effacez-le, mes larmes;

Je les répands en vain; mon amour me trahit,

Mon cœur dicte toujours, et ma main obéit.

Vous, inflexibles murs, secrets dépositaires

Des sincères remords, des peines volontaires;

Rochers affreux, témoins des tourments de mon cœur;

Vous caverne profonde, où regne la terreur;

Vases saints, devant qui vos Vierges gemissantes

Lèvent des yeux éteints et des mains languissantes;

D'ossements précieux triste et froid monument,

Qu'entourent le silence et le recueillement,

Comme vous insensible, à moi-même barbare,

Ces cilices, ces fers que le zèle prépare,

N'ont-ils pas mille fois, par de cruels efforts,

Sans éteindre mes feux, ensanglanté mon corps?

Dieu vainement sur moi veut avoir l'avantage,

L'homme asservit mon cœur, ou du moins le partage;

Mon amour indompté ne connaît plus de frein,

Les larmes et les temps se succèdent en vain.

À mes vives douleurs il n'est point d'intervale;

A l'aspect imprévu d'une Lettre fatale,

Je frémis;... et voyant mon nom baigné de pleurs,

Je tremblai d'y trouver quelques nouveaux malheurs; 
Chaque mot m'effrayait, me remplissait d'allarmes, Je versais, en lisant, un déluge de larmes; Gémissant sur l'ennui de mon triste séjour, Je vous voyais, tantôt esclave de l'Amour;

Tantôt vainqueur, le fuir dans ce lieu solitaire, Où de l'austérité la rigueur salutaire

Détruit les passions dans nos cœurs combattus, Et développe en eux le germe des vertus.

Peignez-moi tous les traits du sort qui vous opprime; Nos cruels ennemis, que la fureur anime, Ne peuvent nous ravir, malgré leurs noirs complots, La douceur de nous plaindre et d'unir nos sanglots. Ne me cachez donc rien, et méprisons leur haine: Abélard aurait-il l'âme plus inhumaine? Lire, verser des pleurs, et pousser des soupirs, Voilà mon sort, hélas! j'y borne mes désirs.

Ce don du Ciel, cet art de peindre la pensée,

Fait renaître l'espoir dans mon âme oppressée;

Par son secours divin, les Amants malheureux Se parlent, quoiqu'absents, et nourrissent leurs feux. Ce Confident chéri les soutient, les console, Et porte leurs soupirs de l'un à l'autre pôle; Par lui, la jeune Amante exprimant ses regrets, Découvre sans rougir ses sentiments secrets; Pour peindre son amour elle prévient l'Aurore, Et dévoile son cœur à l'Amant qu'elle adore (...).

En este erial sombrío, tranquila soledad, hogar de la inocencia, de la virtud asilo, donde mi alma y mis ojos alzados hacia el Cielo, no pueden noche y día contemplarlo bastante, ¿quién vendrá a perturbar mi profundo retiro? Lejos de inquietos goces y de errores mundanos; ¿qué recuerdos reavivan un sedicioso fuego? ¿Mi alma quiere cruzar de ese lugar los muros? En este cruel instante, ¿me reconozco acaso? $¡ A y !$ mi amor aún subsiste... sigo amando a Abelardo, la muy débil Eloísa, adora aún sus trazos.

Nombre horrible y querido... ¡Me otorgáis tanto encanto!

Mas no debo nombrarlos: mi voz he consagrado a celebrar de Dios la Majestad sagrada; guardémoslos en mi alma, que con él allí quede, que sus confusos trazos hogaño se entremezclen. ¡Oh mano no lo escribas!;... mas este dulce nombre ya a mis ojos se muestra... oh lágrimas, borradlo; en vano las derramo; me traiciona mi amor, siempre el corazón dicta y la mano obedece. 
Vos, inflexibles muros, custodios tan secretos

de sinceros pesares, de voluntarias penas;

riscos crueles, testigos del martirio de mi alma; vos profunda caverna, donde reina el terror; santo cáliz, ante el que Vírgenes suplicantes su umbrío mirar alzan y sus lánguidas manos; de osamentos preciosos túmulo triste y frío, que envuelven el silencio y este recogimiento como vos insensible, para mí mismo atroz, los cilicios, los hierros que este celo pergeña, ¿tantas veces no han, por esfuerzos crueles, sin apagar mis fuegos, masacrado mi cuerpo? Sobre mí, Dios en vano quiere tener ventaja, el hombre ocupa mi alma, o la comparte al menos; este indómito amor, ya no conoce freno, las lágrimas y el tiempo se suceden en vano. A mis vivos dolores no hay siquiera intervalo; ante la visión súbita de una carta fatal, estremezco;... y al ver mi nombre entre lágrimas temí encontrar en ella, flamantes infortunios; cada voz me aterraba, me colmaba de angustia, al leerla vertí, un diluvio de lágrimas; gimiendo ante el pesar de mi triste estadía, o bien yo os veía, esclavo del Amor, o bien triunfante, huir a este lugar desierto, donde de la templanza el rigor saludable destruye la pasión del corazón vencido y desarrolla en ellos, de la virtud el germen. Pintad todos los trazos del dolor que os oprime; crueles enemigos, que la cólera exhorta, no pueden despojarnos, pese a sus trampas lóbregas, del dulzor de quejarnos y unir nuestros lamentos.

No me escondáis pues nada, y despreciemos su odio: ¿tendría Abelardo el alma aún más despiadada? Leer, verter las lágrimas, y exhalar un suspiro, ¡Ay, esta es mi suerte donde mi afán recluyo! El don del Cielo o arte de esbozar las ideas, revive la esperanza en mi alma oprimida; para su redención, los aciagos Amantes conversan aunque ausentes, y su amor fortalecen. Un caro Confidente los ampara y consuela, y sus suspiros lleva de uno a otro confín; por él la Amante joven expresa sus pesares, descubre sin rubor sus secretas pasiones; para esbozar su amor a la Aurora previene, y su pasión desvela al amante que adora. 
Veamos a continuación Épitre d'Héloïse à Abaliard, compuesta por Colardeau, versión francesa de la epístola de Eloísa de la creación original de Pope. En este poema, la protagonista, que se haya en la celda del monasterio donde por avatares del destino se encuentra recluida, lee una carta de Abelardo que ha llegado a sus manos y ésta es su respuesta:

Dans ces lieux habités par la simple innocence

Où règne avec la paix un éternel silence,

Où les cœurs asservis à des sévères lois,

Vertueux par devoir, le sont aussi par choix;

Quelle tempête affreuse, à mon repos fatale,

S'élève dans les sens d'une simple vestale?

De mes feux mal éteints qui ranime l'ardeur?

Amour, cruel amour, renais-tu dans mon cœur?

Hélas! je me trompais, j'aime, je brûle encore.

O mon cher et fatal!... Abailard... je t'adore.

Cette lettre, ces traits, à mes yeux si connus,

Je les baise cent fois, cent fois je les ai lus.

De sa bouche amoureuse Héloïse les presse...

Abailard, cher amant, mais quelle est ma faiblesse?

Quel nom dans ma retraite ose-je prononcer?

Ma main l'écrit. Hé bien! mes pleurs vont l'effacer.

Dieu terrible! pardonne; Héloïse souscrit...

Que dis-je? Mon cœur dicte.... et ma plume obéit.

Prisons où la vertu, volontaire victime,

Gémit et se repent, quoique exempte de crime;

Où l'homme, de son être imprudent destructeur,

$\mathrm{Ne}$ jette vers le ciel que des cris de douleur:

Marbres inanimés, et vous, froides reliques,

Que nous ornons de fleurs, qu'honorent nos cantiques,

Quand j'adore Abailard, quand il est mon époux

Que ne suis-je insensible et froide comme vous!

Mon Dieu m'appelle en vain du trône de sa gloire

Je cède à la nature une indigne victoire;

Les cilices, les fers, les prières, les vœux,

Tout est vain, et mes pleurs n'éteignent point mes feux.

Au moment où j'ai lu ces tristes caractères,

Des ennuis de ton cœur secrets dépositaires,

Abailard, j'ai senti renaître mes douleurs.

Cher époux, cher objet de tendresse et d'horreurs,

Que l'amour dans tes bras avait pour moi de charmes!

Que l'amour loin de toi me fait verser des larmes!

Tantôt je crois te voir de myrte couronné,

Heureux et satisfait, à mes pieds prosterné;

Tantôt, dans les déserts, farouche et solitaire,

Le front couvert de cendre, et le corps sous la haire,

Hikma 9 (2010), 25-53 
Desséché dans ta fleur, pâle et défiguré,

A l'ombre des autels, dans le cloître ignoré;

C'est donc là qu'Abailard, que sa fidèle épouse,

Quand la religion, de leur bonheur jalouse,

Brise les nœuds chéris dont ils étaient liés,

Vont vivre indifférents, l'un par l'autre oubliés:

C'est là que, détestant et pleurant leur victoire,

Ils fouleront aux pieds et l'amour et la gloire.

Ah! plutôt écris-moi: formons d'autres liens,

Partage mes regrets... je gémirai des tiens.

L'écho répètera nos plaintes mutuelles;

L'écho sert les amants malheureux et fidèles.

Le sort, nos ennemis, ne peuvent nous ravir

Le plaisir douloureux de pleurer, de gémir;

Nos larmes sont à nous, nous pouvons les répandre:

Mais Dieux seul, me dis-tu, Dieu seul y doit prétendre.

Cruel! Je t'ai perdu, je perds tout avec toi.

Tout m'arrache des pleurs... tu ne vis plus pour moi.

C'est pour toi... pour toi seul que couleront mes larmes,

Aux pleurs des malheureux Dieu trouve-t-il des charmes?

Ecris-moi, je le veux: ce commence enchanteur,

Aimable épanchement de l'esprit et du cœur,

Cet art de converser, sans se voir, sans s'entendre,

Ce muet entretien, si charmant et si tendre,

L'art d'écrire, Abailard, fut sans doute inventé

Par l'amante captive et l'amant agité;

Tout vit par la chaleur d'une lettre éloquente,

Le sentiment s'y peint sous les doigts d'une amante.

En esta estancia donde sólo el candor reside

donde con la paz reina un eterno silencio,

donde el alma rendida a leyes inflexibles,

por deber virtuosa, y aún por elección;

¿qué horrible tempestad, a mi fatal reposo

se eleva a los sentidos de una simple vestal?

¿De mis fuegos aún vivos, quién revive el ardor?

Amor, cruel amor, renaces en mi alma?

¡Ay! confundida estaba, amo aún de amor ardo.

¡Oh querido y fatal!... Abelardo... te adoro.

Esta carta, estos trazos, me son tan familiares, cien veces yo los beso y los leo otras cien.

con su boca amorosa Eloísa los oprime...

Abelardo, mi amado, ¿mas cuál es mi flaqueza?

¿Qué nombre en mi retiro, me atrevo a pronunciar?

Mi mano lo ha escrito, lo ha de borrar mi llanto.

¡Terrible Dios!, perdón; Eloísa se resigna...

¿Qué digo? Mi alma dicta... y mi pluma obedece.

Hikma 9 (2010), 25-53 
Prisión donde virtud, víctima voluntaria

solloza y se arrepiente, aunque exenta de crimen; donde el hombre imprudente, de su ser destructor, sólo hacia el cielo lanza lamentos de dolor: inanimados mármoles, y vos, frías reliquias, que de flores ornamos, lo que honran nuestros cantos, cuando a Abelardo adoro y cuando él es mi esposo, ¿no soy acaso fría y como vos distante? Mi Dios me llama en vano al trono de su gloria yo cedo a la natura una indigna victoria; los cilicios, los hierros, deseos y oraciones, todo en vano, y el llanto mi fuego no consume. En el tiempo que leo aquestas tristes letras, misteriosas guardianas del pesar que te embarga, he sentido, Abelardo, renacer mi dolor.

Esposo amado, objeto de ternura y horror, ¡El amor en tus brazos me ofrecía tanto encanto! ¡Lejos de ti, el amor, cuánto llanto me roba! Ora creo distinguirte, de mirto coronado, feliz y satisfecho, a mis pies postergado; ora, ya en los abismos, arisco y solitario, con la frente cetrina y el cuerpo bajo el sayo, marchitado en tu flor, níveo y desfigurado, a la sombra del ara, en el claustro ignorado; allí pues Abelardo y su leal esposa, cuando la religión, de su pasión celosa, rasga los dulces lazos, que a ambos nos unían, vivirán impasibles, uno de otro olvidados: allí pues detestando y llorando su triunfo, ellos pisotearán, y el amor y la gloria.

No dejes de escribirme: creemos nuevos lazos, comparte mis anhelos... yo plañiré los tuyos.

El eco imitará nuestros mutuos lamentos; el eco a los amantes desventurados sirve. No podrá el enemigo, la suerte arrebatarnos ni el placer doloroso, de llorar y gemir; Nuestras son nuestras lágrimas, y podemos verterlas: sólo Dios, como dices, sólo Dios ha de hacerlo. ¡Cruel! Yo te he perdido, pierdo todo sin ti. Todo desgarra mi alma... para mí ya no vivo. Por ti, por ti tan sólo... he de verter mis lágrimas, ¿en el llanto del mísero, encuentra Dios placer? Escríbeme, así quiero: este grato comienzo, amable desahogo del corazón y el alma, el arte de charlar, sin verse, sin oírse, esta muda afición, tan agradable y dulce, el arte de escribir fue sin duda creado 
por la amante cautiva y el amante agitado;

vivir por el ardor de una elocuente carta,

dibujado el sentir de manos de la amante.

\section{REFLEXIONES SOBRE LA COMPOSICIÓN DE POPE Y LA VERSIÓN FRANCESA DE COLARDEAU.}

La poesía es la forma de escritura literaria que más dificultades plantea a la traducción, pues tanto forma como fondo deberán ser preservados. Asimismo es el arte literario que tiende a ser lo más estético posible dado que la escritura en verso supone rima, sonido, ritmos y metáforas. El traductor se enfrenta a todo un sistema complejo y no solamente a un verso aislado, razón por la cual tiene que establecer una escala de prioridades para traducir, puesto que si el poeta privilegió la rima, el traductor se concentrará sobre todo en este aspecto, aunque en general el sacrificio, la compensación y la medida son las claves para traducir un poema. No cabe duda que en poesía sonido y sentido están estrechamente relacionados, además es lógico pensar que no existe una única interpretación del texto, dado que cada traductor lo entiende de manera diferente y puede crear a su vez distintas versiones de un mismo poema. Estas reflexiones legitiman cualquier versión de calidad, pero tengamos en cuenta que el poeta no plasma en su obra sus ideas de manera tan clara como un hablante cualquiera, porque lo que le empuja a componer es su estado de ánimo, un sentimiento, un deseo de crear literatura, de ahí que las palabras que elige el poeta, pudiendo ser sencillas, en el interior del texto y en asociación con los demás términos, amplifican sus significados.

Tras resolver estas primeras incertidumbres, al traductor de poesía se le plantea el problema de la recreación: los traductores afrontan la ardua tarea de reproducir los estados del alma de un ser humano y ello con los medios que otra lengua meta les ofrece. Dependiendo del grado de elaboración y consecución del texto meta, podemos definir el tipo de traducción a la que se ajusta siguiendo los requerimientos de las diferentes clasificaciones $^{10}$ de traducción poética, donde quedan incluidas desde adaptaciones en prosa hasta recreaciones ideales de poemas. Por otra parte, es posible que el traductor-poeta se aparte por completo del original, permitiendo que su propia subjetividad entre en juego, dando luz así a un nuevo poema inspirado o basado en el original, estaríamos ante la

\footnotetext{
${ }^{10}$ Numerosos autores han propuesto a lo largo del siglo $\mathrm{XX}$ diferentes clasificaciones de traducción poética (J. S. Colmes, 1969; A. Lefevere, 1975; J.-Y. Masson 1992) pero nosotros queremos destacar la aportación de E. Etkind (1982). Este autor divide las traducciones poéticas en seis grupos: "Traduction-Information", "Traduction-Interprétation", "TraductionAllusion", "Traduction-Approximation", "Traduction-Recréation" y "Traduction- Imitation".
} 
"traduction-imitation". Considerada la traducción bajo este prisma, el traductor se aleja del original para crear un poema personal, caso concreto de las traducciones-versiones realizadas por Feutry y Colardeau partiendo del texto original de Pope Eloise to Abelard.

Redactada en "heroic couplets" ${ }^{11 "}$ la epístola de Alexander Pope consta de 366 versos y está construida en tres partes, según un eje a la vez temporal y espacial. Pope nos presenta un binomio temporal presentepasado: partiendo del duro y desesperanzador presente, donde la protagonista nos describe el desierto y melancólico convento del Paraclet, retrotrae a Eloísa al pasado, mediante la técnica de la analepsis y resucita el tiempo de la felicidad. Al final de la obra, Eloísa proyecta su alma en el futuro, experimentando una visión de la eternidad y del reino de los cielos, que conforma un eco purificado de la primera parte. Este primer segmento de la composición de Pope, (versos del 1-58) que hemos elegido para exponer las versiones de los autores franceses anteriormente citados, describen la escena en la que Eloísa recibe una carta de Abelardo y se esfuerza en responderla, a pesar de su desconcierto. La carta reaviva la pasión que ha permanecido siempre latente en su corazón y despierta el dolor por la separación de su amado, que ni el aislamiento, ni la dedicación a Dios han podido atenuar. Ante el nombre de Abelardo, Eloísa vuelve a sentir la llama del amor tan intensamente como el primer día, una pasión que arde en ella y que perturba sus sentidos, pero a la que se abandona, sintiendo un extraño placer en los sufrimientos que le acarrea, pues le recuerdan que sigue viva, que es capaz de amar a pesar del tiempo, de la lejanía y de la reclusión. En esta introducción, Eloísa suplica y exhorta a Abelardo a que le escriba, que comparta con ella sus penas y se aferra a esta posibilidad de comunicarse con el amado para poder sentir su presencia.

La estructura anatómica de este texto puede representarse por los siguientes ejes semánticos: la constatación del sentimiento del amor, la religión como castradora de una pasión sin límites y la escritura como medio de renovación de los vínculos del amor.

En lo que respecta al primer eje, analizaremos la trascendencia de la recepción de la carta de Abelardo, la efusión de un sentimiento amoroso incontrolable y la subjetiva significación de las palabras de Abelardo entendidas como promesas de amor. El acontecimiento detonante del inicio del intercambio epistolar entre Eloísa y Abelardo se produce cuando llega a manos de la protagonista una carta de su amado que iba dirigida a un amigo. Este hecho es doblemente significativo, ya que por un lado permite

${ }^{11}$ El "heroic couplet" es la forma tradicional de la poesía épica, narrativa o descriptiva inglesa. Estos poemas están construidos mediante una sucesión de pentámetros yámbicos de rima masculina. 
que los amantes, tras años de soledad y olvido, reanuden el contacto y que este intercambio epistolar se convierta en una verdadera exaltación de un sentimiento mutuo. Por otro lado, la recepción de esta misiva da origen a una obra singular como es Historia Calamitatum ${ }^{12}$ y a la propia composición de Alexander Pope.

Los primeros versos de esta composición dejan clara evidencia de que ante la lectura de la carta de Abelardo, súbitamente se reaviva la pasión en el corazón de Eloísa y los recuerdos le hacen olvidar el reducto donde se haya enclaustrada. Destacamos la clara antítesis de tonos entre los tres primeros versos donde el ritmo lento y pausado acentúan la monotonía y tristeza a la que se ve reducida Eloísa, con la rápida sucesión de interrogaciones retóricas iniciadas en el verso 4, que concluyen con una admiración que rompe el ritmo y el propio verso 7 , que no es más que la constatación de los verdaderos sentimientos de Eloísa por Abelardo:

"In these deep solitudes and awful cells,

1

Where heav'nly-pensive contemplation dwells,

And ever-musing melancholy reings;

What means this tumult in a vestal's veins?

Why rove my thoughts beyond this last retreat?

Why feels my heart its long-forgotten heat?

Yet, yet I love!-From Abelard it came,

And Eloisa yet must kiss the name."

Los tres primeros versos están claramente marcados por los elementos temporales tales como el complemento circunstancial "In these deep" o la oración de relativo "Where", que introducen el espacio de Eloísa, descrito a través de dos sucesiones de adjetivo antepuesto con claro matiz subjetivo y sustantivo "deep solitudes and awful cells", signos evidentes de la profunda soledad en la que se encuentra y la falta de libertad que soporta. Este contexto, tan propicio para la "contemplation" y la "melancholy" no ha podido enterrar los apasionados sentimientos de Eloísa: ella no está sola, pues Abelardo vive en ella, en lo más profundo de su alma, "why feels my heart its long-forgotten heat?' y esta pasión supera los

${ }^{12}$ Historia Calamitatum o Abaelardi ad amicum suum consolatoria: obra autobiográfica escrita en latín por el famoso escolástico Pedro Abelardo. Se trata de la primera obra autobiográfica occidental, escrita en forma de carta y claramente influida por las Confesiones de San Agustín. Uno de los principales méritos de esta obra es el hecho de mostrar al lector una visión de la vida intelectual de un París anterior a la creación de las universidades, un periodo de gran agitación intelectual marcado por la presencia de la Iglesia y por supuesto, la exposición de la importante relación que mantuvo con Eloísa. 
límites de su celda "why rove my thoughts beyond this last retreat?". Motivos por los cuales siente la necesidad de gritar su amor "yet, yet I love?" al tiempo que la obligación de expresar que la llama sigue viva "Eloisa yet must kiss the name", no sólo con palabras sino también con gestos, es decir, besando el nombre de Abelardo escrito en la carta y reiterar mediante el adverbio "Yet" que su pasión "long-forgotten" jamás murió. Es notorio destacar que en estos primeros versos aparecen los nombres de los dos personajes principales, emisor y receptor de la misiva, sin embargo, el nombre de Abelardo sólo se repetirá dos veces más en el extracto seleccionado, siendo sustituido por la reiterada metonimia "name". Veamos a continuación la traducción que Colardeau hace de estos primeros versos:

Dans ces lieux habités par la simple innocence

Où règne avec la paix un éternel silence,

Où les cœurs asservis à des sévères lois,

Vertueux par devoir, le sont aussi par choix;

Quelle tempête affreuse, à mon repos fatale,

S'élève dans les sens d'une simple vestale?

De mes feux mal éteints qui ranime l'ardeur?

Amour, cruel amour, renais-tu dans mon cœur?

Hélas! je me trompais, j'aime, je brûle encore.

O mon cher et fatal !... Abailard... je t'adore.

Cette lettre, ces traits, à mes yeux si connus,

Je les baisse cent fois, cent fois je les ai lus.

De sa bouche amoureuse Héloïse les presse...
1

5

La primera evidencia apreciable en la traducción francesa es la extensión del texto. Mientras que Pope concentra las ideas expuestas en este primer eje semántico en 8 versos, Colardeau aumenta el número a 13. Esta ampliación se debe en primer lugar a que el autor francés desarrolla en varios versos los elementos significativos de un solo verso inglés.

What means this tumult in a vestal's veins?

Quelle tempête affreuse, à mon repos fatale,

S'élève dans les sens d'une simple vestale?

And Eloisa yet must kiss the name."

Je les baisse cent fois, cent fois je les ai lus.

De sa bouche amoureuse Héloïse les presse...

Las dos ampliaciones muestran el mismo objetivo: aumentar el lirismo y el dramatismo de las escenas, valiéndose de hipérboles como "tempête affreuse", "repos fatal", o de reiteraciones hiperbólicas tales como "cent fois..., cent fois". En el texto francés, además de estas ampliaciones 
lingüísticas, se incorporan variaciones que no se recogen en el texto original que intensifican el lirismo del verso: "Où les cœurs asservis à des sévères lois, / vertueux par devoir, le sont aussi par choix," (vv. 3, 4); otras aportan claridad describiendo elementos omitidos en el texto original: "Cette lettre, ces traits, à mes yeux si connus" (v.11). Pero centrémonos en el verso principal de este grupo, donde Eloísa confiesa en voz alta su amor (vv 7,8):

Yet, yet I love!-From Abelard it came,

(vv 7,8)

And Eloisa yet must kiss the name.

Esta eclosión de sentimientos da testimonio de varias nociones absolutas: la idea de que Eloísa nunca ha dejado de amar, que el causante de tanto amor y dolor no es otro que el propio Abelardo y que es tan grande su pasión hacia él que se siente obligada a expresarla físicamente, besando el objeto que más se identifica con el amado: su nombre escrito en la carta. En la versión de Colardeau, sólo el primero se aproxima al verso de Pope, en tanto en cuanto se mantiene la exclamación, modulada por la introducción de dos adjetivos antitéticos "cher" y "fatal". El autor francés separa mediante signos ortográficos no sólo los dos hemistiquios del verso, sino que destaca, a modo de vocativo, el nombre del amado, para concluir y enfatizar el efecto del verbo "adorer" al final de verso y que constituya una rima pareada con "encore", reforzándose así la idea de un amor eterno. Los tres versos siguientes desarrollan mediante gradación la emoción que Eloísa siente al contemplar la carta de Abelardo: en primer lugar reconoce unos trazos tan familiares y queridos para ella, seguidamente siente la imperiosa necesidad de besarlos, para posteriormente estrecharlos con su "bouche amoureuse". La intensidad de la escena aumenta gradualmente. (vv 10-13).

Con la siguiente estrofa de Pope ponemos de manifiesto una de las ideas que presentábamos en este primer eje semántico: la efusión de un sentimiento amoroso incontrolable. A lo largo de estos ocho versos, Eloísa nos describe la limitación de su propia voluntad, incapaz de someterse al olvido de un amor de tal magnitud. A pesar de que la razón ordena a su corazón que oculte su pasión y no le permita exteriorizarla, y suplique a su mano que se refrene -idea reforzada mediante imperativos "Nor pass these lips", "hide it, my heart", "O write it not, my hand"- el poder del amor es tan intenso que Eloísa sólo puede dejarse llevar, anulada su voluntad, pues el corazón es el que dicta y toda ella se somete, empezando por la mano: "In vain lost Eloisa weeps and prays,/ her heart still dictates, and her hand obeys.". Veamos la estrofa completa (vv. 9-16):

Dear fatal name! Rest ever unreveal'd,

Nor pass these lips in holy silence seal'd. 
Hide it, my heart, within that close disguise, Where mix'd with God's, his lov'd idea lies: $O$ write it not, my hand-the name appears Already written-wash it out, my tears!

In vain lost Eloisa weeps and prays,

Her Heart still dictates, and her hand obeys.

La versión de Colardeau es más libre y breve. De estos cinco versos, tres son los que mantienen las ideas expresadas por Pope: la osadía de pronunciar el nombre de Abelardo; la mano que por voluntad propia escribe un nombre proscrito y las lágrimas que han de borrarlo; y la personalidad adquirida por dos miembros de su cuerpo, el corazón y la mano, aunque en este caso concreto, la metonimia se expresa por medio de una "plume". En estos versos la intensidad de la escena no se representa mediante imperativos, no hay órdenes directas de Eloísa, sino a través de interrogaciones retóricas. La única admiración expresa es la petición de perdón a Dios por su pecado -la imposibilidad de que su propia razón controle su corazón- y que sea éste el que domine su cuerpo y su mente. Ante tal evidencia, Eloísa acepta su derrota "Héloïse souscrit..." y confiesa su debilidad "mais quelle est ma faiblesse?".

Es reseñable que a pesar de las mutaciones sufridas en el texto francés, el significado mantiene cierta proximidad. Por el contrario los cambios en los referentes son muy relevantes, consiguiéndose así una condensación semántica:

Abailard, cher amant, mais quelle est ma faiblesse?

Quel nom dans ma retraite ose-je prononcer?

Ma main l'écrit. Hé bien! mes pleurs vont l'effacer.

Dieu terrible! pardonne; Héloïse souscrit..

Que dis-je? Mon cœur dicte.... et ma plume obéit.

El segundo eje semántico, recogido en los versos 17-40 del texto original, es la religión como castradora de una pasión sin límites. Este apartado nos permite poner de relieve los elementos que emergen de este plano genérico tales como las naturalezas muertas; la oscuridad, la cerrazón y la soledad; los sacrificios impuestos a Eloísa; y la confirmación de que el amor de nuestra protagonista por Abelardo es su verdadera religión.

Relentless walls! whose darksome round contains

Repentant sighs, and voluntary pains:

Ye rugged rocks! which holy knees have worn;

Ye grots and caverns shagg'd with horrid thorn!

Shrines! where their vigils pale-ey'd virgins keep, 
And pitying saints, whose statues learn to weep! Though cold like you, unmov'd, and silent grown, I have not yet forgot myself to stone.

All is not Heav'n's while Abelard has part,

Still rebel nature holds out half my heart;

Nor pray'rs nor fasts its stubborn pulse restrain,

Nor tears, for ages, taught to flow in vain.

Soon as thy letters trembling I unclose,

That well-known name awakens all my woes.

Oh name for ever sad! for ever dear!

Still breath'd in sighs, still usher'd with a tear.

I tremble too, where'er my own I find,

Some dire misfortune follows close behind.

Line after line my gushing eyes o'erflow,

Led through a sad variety of woe:

Now warm in love, now with'ring in thy bloom,

Lost in a convent's solitary gloom!

There stern religion quench'd th' unwilling flame,

There died the best of passions, love and fame.

La historia de Abelardo y Eloísa relata que Abelardo, tras sufrir el ataque y la mutilación, comenzó a sumirse en una gran depresión. Se había convertido en un ser despreciable, algo así como la mitad de un hombre. Eloísa, joven aún, protestaba ante el mundo y ante Dios; se negaba a aceptar la pavorosa ablación de su amado y le repetía que seguiría queriéndolo toda la vida. Abelardo, finalmente, decidió hacerse monje, a pesar de las protestas de su mujer: no tenía sentido permanecer en el mundo. Esta decisión obligó a Eloísa a seguir sus pasos y tomar los votos, no obstante pasó el resto de su vida desesperadamente enamorada de Abelardo. Nunca perdonó a su tío, ni a la iglesia, ni a Dios, por el cruel destino al que la habían conducido y porque le habían robado la felicidad. Abelardo resignado, llegó a afirmar que su tragedia era un merecido castigo divino: había pecado con Eloísa. Eloísa, en cambio, se sentía cada día más rebelde contra el mundo. Sus cartas reflejan la desolación de una mujer atormentada hasta el final de su vida. El resentimiento de Eloísa está netamente reflejado en estos versos, que dan testimonio de su indocilidad e inconformismo.

En la primera parte de esta serie de versos (del 17-28), Eloísa establece un diálogo con los únicos elementos que la rodean: muros, rocas, grutas, cavernas, capillas, vírgenes, santos..., testigos implacables de su desdicha, de sus suspiros y de sus penas. Esta sucesión de apelativos le permite realizar una subjetiva descripción del espacio que la constriñe. Estas naturalezas muertas, hurañas y despiadadas, han sido la única compañía de Eloísa y sus únicos confidentes durante muchos años, sin 
embargo se han mantenido insensibles a su desesperación. Eloísa nos describe un escenario cruel: "relentless walls", "rugged rocks! which holy knees have worn", "grots and caverns shagg'd with horrid thorn", "shrines! where their vigils pale-ey'd virgins keep", "saints, whose statues learn to weep!". Sin embargo no ha sucumbido ante la actitud impertérrita de sus acompañantes, y aunque ahora se muestre fría, inmóvil y silenciosa "cold like you, unmov'd and silent", ella sigue viva, no se ha convertido en piedra "I have not yet forgot myself to stone", su corazón no se ha endurecido o enfriado, pues siente dentro de él la llama de Abelardo. La naturaleza rebelde y contestataria de Eloísa la impulsa a ofrecer a su amado "half my heart", negándose así a entregarse por entero a Dios. Ni su alma, ni su corazón se doblegarán, siguen perteneciendo a su único Dios: Abelardo.

Los versos 29 al 40, sustentados por las metonimias "name" y "letters" referencias indudables a la persona de Abelardo, describen el amor y el dolor que siente Eloísa al tener frente a ella un objeto que procede de su amado, cuyo nombre aparece escrito y donde se recoge su propio sentir y su propio sufrimiento. La gradación in crescendo de los sentimientos de Eloísa nos permiten percibir que su aflicción se convierte en tormento a medida que sus ojos recorren los trazos de Abelardo, "line after line my gushing eyes o'erflow", y que el afecto que su corazón ha mantenido oculto durante tanto tiempo, ahora estalla en abrasadora llama y florece como una flor en primavera: "Now warm in love, now with'ring in thy bloom". La eclosión de tales sensaciones deriva en una acusación aplastante a la religión como cercenadora de un sentimiento puro, de un destino en común y de un futuro prometedor. Por ello, y a modo de conclusión, Pope cierra la estrofa con dos versos: el primero recoge la idea de la religión como aniquiladora de cualquier pasión y el segundo resume el final de su trágica historia:

There stern religion quench'd th' unwilling flame, There died the best of passions, love and fame.

Veamos ahora la versión de Colardeau:

Prisons où la vertu, volontaire victime,

Gémit et se repent, quoique exempte de crime;

Où l'homme, de son être imprudent destructeur,

Ne jette vers le ciel que des cris de douleur:

Marbres inanimés, et vous, froides reliques,

Que nous ornons de fleurs, qu'honorent nos cantiques

Quand j'adore Abailard, quand il est mon époux

Que ne suis-je insensible et froide comme vous

Mon Dieu m'appelle en vain du trône de sa gloire 
Je cède à la nature une indigne victoire;

Les cilices, les fers, les prières, les vœux,

Tout est vain, et mes pleurs n'éteignent point mes feux.

Aunque la versión de Colardeau es muy libre, en el plano semántico, podemos justificar ciertos aspectos en común que se establecen con el texto de Pope: el texto francés reproduce el diálogo entre Eloísa y los objetos que la rodean "Marbres inanimés, et vous, froides reliques"; se recrea la descripción espacial barnizada con tono angustioso, lugares que causan tormento incluso a los inocentes y se hace referencia a ciertas naturalezas muertas "prisons", "marbres", "reliques"; se detalla la victoria del amor sobre la religión y se especifica que ni los martirios físicos, ni la oración, ni los intentos voluntarios de Eloísa por ceder a la pasión han podido apagar el fuego de su corazón: "Tout est vain, et mes pleurs n'éteignent point mes feux". La primera serie de versos (del 19 al 26) se sustentan en dos sustantivos que van a regir la sintaxis de este grupo oracional: "prisons" del que dependen dos oraciones de relativo con valor locativo "où la vertu.... / où l'homme..." que introducen dos sustantivos abstractos, "vertu" y "homme" metáforas de los personajes principales, Eloísa y Abelardo. Esta figura retórica permite a Colardeau dejar patente que Eloísa eligió voluntariamente su destino tras conocer la tragedia de Abelardo y que en su retiro, "gémit et se repent" a pesar de saberse inocente del crimen que se le imputa "quoique exempte de crime", su único delito ha sido amar con toda su alma. En cuanto a Abelardo "de son être imprudent destructeur", habiendo aceptado su desdichado destino como castigo divino, no puede más que llorar su dolor y elevar al cielo sus plegarias implorando perdón. El segundo de los sustantivos que rige el siguiente grupo sintáctico es "marbres" unido por conjunción copulativa a "reliques", ambos calificados con adjetivos que implican la falta de vida como son "inanimés" y "froides". A ellos se refiere Eloísa como símbolos de los atributos religiosos (himnos, rezos y flores) y de los ritos que la religión impone "ornons de fleurs" y "honorent nos cantiques". Todas estas referencias a la doctrina católica son expuestas para evidenciar la protesta de Eloísa, su rechazo a esta insensibilidad, soledad y reprobación. Ella quiere gritar su "adoración" por su amado, su "époux", contradiciendo así a todo aquel que pretenda ofenderla, su amor es fiel, puro y legal, por ello se congratula de no haber cedido a los dictados del dogma, sino mantenerse firme y defender, incluso ante Dios, sus sentimientos. La reiteración de "vain", en el verso 27 en forma de adverbio y en el verso 30 de adjetivo, muestran la insistencia de que todos los sacrificios son inútiles, los tormentos sufridos, los arrepentimientos, las torturas físicas o de conciencia, no han servido de nada, pues todo lo sufrido sólo ha contribuido a reforzar su amor y a salvaguardarlo de todo y de todos. 
Au moment où j'ai lu ces tristes caractères,

Des ennuis de ton cœur secrets dépositaires,

Abailard, j'ai senti renaître mes douleurs.

Cher époux, cher objet de tendresse et d'horreurs,

Que l'amour dans tes bras avait pour moi de charmes! 35

Que l'amour loin de toi me fait verser de larmes!

Tantôt je crois te voir de myrte couronné,

Heureux et satisfait, à mes pieds prosterné;

Tantôt, dans les déserts, farouche et solitaire,

Le front couvert de cendre, et le corps sous la haire,

Desséché dans ta fleur, pâle et défiguré,

A l'ombre des autels, dans le cloître ignoré;

C'est donc là qu'Abailard, que sa fidèle épouse,

Quand la religion, de leur bonheur jalouse,

Brise les nœuds chéris dont ils étaient liés,

Vont vivre indifférents, l'un par l'autre oubliés:

C'est là que, détestant et pleurant leur victoire,

Ils fouleront aux pieds et l'amour et la gloire.

En el grupo de versos que constituye la estrofa anterior (del verso 27 al 49), los protagonistas del diálogo han cambiado, ahora Eloísa se dirige a Abelardo, personajes recogidos en el pronombre personal "Je" del verso 27 y en el vocativo "Abailard" del v. 29. Ello explica que abunden los pronombres personales y los adjetivos posesivos de primera y segunda persona del singular. Los cuatro primeros versos representan la confesión amorosa de Eloísa, cuyo detonante ha sido la lectura de la carta de Abelardo: al conocer la desdicha de su amado, Eloísa se ha dejado llevar y ha visto rebrotar el amor. De nuevo reitera, mediante vocativo, que Abelardo es su esposo "cher époux", dejando constancia de la legalidad de su relación, e insiste en este hecho en el verso 43 "sa fidèle épouse", por un lado para calmar los celos de Abelardo y para dejar claro que su unión está bendecida por Dios. Los sustantivos referidos al cuerpo humano se presentan como campo léxico: "cœur, bras, pieds, front, corps". Su amor es verdadero y su dolor y su pasión la sufren y la sienten con el alma y con el cuerpo: "cher objet de tendresse et d'horreurs". Ahora el lenguaje es más directo, más expresivo, cargado de lirismo y sensibilidad, para lo que Colardeau utiliza como recurso estilístico los paralelismos sintácticos antitéticos:

Que l'amour dans tes bras avait pour moi de charmes! 35

Que l'amour loin de toi me fait verser de larmes! 
Dos versos en apariencia opuestos por los términos antagónicos "dans tes bras", "loin de toi", "charmes", "larmes", que manifiestan la misma afirmación: Eloísa sólo es feliz al lado de su esposo y amor.

Tantôt je crois te voir de myrte couronné,

Heureux et satisfait, à mes pieds prosterné;

Tantôt, dans les déserts, farouche et solitaire,

Le front couvert de cendre, et le corps sous la haire,

Desséché dans ta fleur, pâle et défiguré,

A l'ombre des autels, dans le cloître ignoré;

El adverbio "tantôt", que inicia los versos alternos 37 y 39, reproduce un segundo paralelismo antitético que ha sufrido la elipsis del verbo. Mediante este recurso, Colardeau muestra a través de los ojos de Eloísa las dos imágenes de Abelardo, en el pasado y en el futuro, haciendo una analepsis y una prolepsis. "Tantôt je crois te voir de myrte couronné / Heureux et satisfait, à mes pieds prosterné": Eloísa vuelve al pasado junto a Abelardo y recuerda aquellos días en que siendo él un ilustre y laureado filósofo, "de myrte couronné", la aleccionaba en conocimientos universales y le hablaba de amor rendido a sus pies. Con la prolepsis, Eloísa se aterroriza al pensar en la muerte de Abelardo, cubierto de ceniza, desfigurado y olvidado por todos "dans le cloître ignoré". Los últimos versos de esta estrofa retoman la idea principal de nuestro eje semántico: la religión castradora de la ilusión y del amor. En ellos Eloísa se queja de que sea la religión, "de leur bonheru jalouse", la causante de sus desdichas, la que cercena sus lazos "Brise les nœuds chéris", la que los separa, siendo marido y mujer, la que los condena al olvido "Vont vivre indifférents, l'un par l'autre oubliés", la que no soporta que su amor perdure.

El tercer eje semántico al que aludíamos al principio de este apartado es la escritura como medio de renovación de los vínculos del amor. Los versos 41-58 de Pope son clara muestra de la exhortación que Eloísa hace a Abelardo para que continúe escribiéndole. Asimismo, la escritura se presenta como medio que permite intercambiar alegría y dolor, que no tiene límites físicos ni está restringida a un determinado emisor. En la primera carta que Eloísa envía a Abelardo confiesa una petición de palabra. A través de argumentos que se deslizan y se entrelazan en el texto, Eloísa implora trazos de la mano de su amado. Como una oda a la palabra, Eloísa elogia su poder. Sus cartas no sólo contienen un discurso acerca del amor, sino el discurso de su amor. Las palabras que ahí se erigen nos revelan el poder de salvación o de condena que puede conllevar este discurso. Las palabras, mensajeras insignes del amor, no van al viento sino al alma. Su fuerza colinda con lo sagrado, con todo lo sagrado que puede llegar a ser el amor. 
$\mathrm{Ni}$ el tiempo ni la ausencia, lograron siquiera rozar el amor que Eloísa profesara algún día a Abelardo. Este sentimiento, cristalizado y creciente a la vez, permaneció, inquebrantable entre los infortunios. Ahora, en el presente de Eloísa surgía la palabra como posibilidad del reencuentro amoroso, como un antídoto contra la nostalgia y la melancolía. A partir de esta carta se suceden numerosas misivas en las que Abelardo sólo habla del amor a Dios y ella le pide palabras de amor y consuelo, temiendo ser olvidada por el amor de su vida, pero no consigue que Abelardo le hable como un amante sino sólo como un maestro que pretende consolarla. Afortunadamente, la última carta conocida de Abelardo a Eloísa, termina con una oración compuesta para ella, su lenguaje abandona la abstracción y, por primera vez se vuelve íntimo y cálido. Evidentemente, el recuerdo de la pasión había conseguido romper la solidez doctrinal de su amado Abelardo.

Son así las cartas de amor de Abelardo y Eloisa, un testimonio del amor vivido en la distancia, un amor que duró hasta el fin de sus días, desde el reclutamiento de la vida monacal y el recuerdo de las pasiones vividas. Veamos los versos de Pope donde se resumen estas afirmaciones:

Yet write, oh write me all, that I may join

Griefs to thy griefs, and echo sighs to thine.

Nor foes nor fortune take this pow'r away;

And is my Abelard less kind than they?

Tears still are mine, and those I need not spare,

Love but demands what else were shed in pray'r;

No happier task these faded eyes pursue;

To read and weep is all they now can do.

Then share thy pain, allow that sad relief;

$A h$, more than share it! give me all thy grief.

Heav'n first taught letters for some wretch's aid,

Some banish'd lover, or some captive maid;

They live, they speak, they breathe what love inspires,

Warm from the soul, and faithful to its fires,

The virgin's wish without her fears impart,

Excuse the blush, and pour out all the heart,

Speed the soft intercourse from soul to soul,

And waft a sigh from Indus to the Pole.

En la primera parte de la estrofa estamos ante una clara exhortación de Eloísa hacia Abelardo para que le escriba, dicha apelación se produce mediante la reiteración del imperativo "write" reforzado con los complementos de tiempo "yet" que otorgan inmediatez y con el complemento directo "all" que alude a la totalidad. En este sentido la exigencia de Eloísa apunta al presente más inmediato y a la necesidad de 
saber todo sobre Abelardo, completando su petición con una intencionalidad final "that I may join / griefs to the griefs", y que queden unidas las penas de ambos amantes, representados mediante las metonimias "griefs"; de este modo el dolor compartido es más soportable. Mediante la interrogación retórica del verso 52, "And is my Abelard less kind than they?", Eloísa barniza su incitación con un sutil tono irónico y desafiante: si "Nor foes nor fortune" pueden impedir que los amantes puedan reanudar su relación y que puedan compartir su dolor y su amor, ¿acaso sería Abelardo capaz de hacerlo? Con esta cuestión, Eloísa plasma su temor ante la posibilidad de que Abelardo la haya olvidado. El tono de los versos siguientes cambia (vv. 53-56). Ahora Eloísa, abatida, se refugia en su pena. Resignada sabe que el cruel sentimiento que la atormenta es sólo suyo, mas no necesita compartirlo, haciendo clara referencia a que no va a exigir de Abelardo promesas de amor, afirmación intensificada por el vocativo "Love" (v. 54). Los ojos de Eloísa, acostumbrados a verter infinitas lágrimas por las oraciones y por los recuerdos, sólo aspiran a ser el medio de expresión de sus sentimientos más ocultos y ser los emisarios que le trasmitan las palabras de su amado: "No happier task these faded eyes pursue;/ To read and weep is all they now can do".

En la última serie de versos (57-66), Eloísa expone diferentes argumentos que justifican las bondades del intercambio epistolar con el único objetivo de animar a Abelardo para que responda a sus cartas. Este alegato se inicia con la primera justificación que Eloísa expone: mediante las cartas Abelardo podrá compartir su dolor, así encontrará cierto alivio a los tormentos que lo torturan. Este razonamiento se presenta a modo de sentencia lógica gracias al adverbio de modo: "Then share thy pain"; y se completa con una gradación aumentativa cargada de generosidad y altruismo: "more than share it! give me all thy grief". El amor que Eloísa siente por Abelardo es tan inmenso que prefiere soportar ella misma toda la carga del tormento, a saber que su marido sufre en silencio. El segundo argumento que Eloísa refiere es la comparación de su estado con el de otras parejas anónimas "banish'd lover", "some captive maid", amantes que supieron mantener su amor, el contacto entre ellos, intercambiando a través de las cartas sus sensaciones, sus anhelos, sus miedos..., pero gracias a las cuales ahora dichos amantes viven, respiran lo que amor inspira, manteniendo el fuego de su amor y fieles a ellos mismos y a la pasión que comparten: "They live, they speak, they breathe what love inspires, / Warm from the soul, and faithful to its fires,". En la última justificación Eloísa defiende un interés personal y arguye, que gracias a la escritura, ella misma, "the virgin", puede sin temor transmitir sus deseos, ocultando el rubor y ante todo desahogar su corazón, lo que permite que las almas de 
los amantes se vuelvan a unir en una "soft intercourse", obviando la distancia que pueda existir entre ellos, "waft a sigh from Indus to the Pole".

Colardeau, por su parte, añade dos versos, quedando la estrofa compuesta por 20 versos:

Ah! plutôt écris-moi: formons d'autres liens,

Partage mes regrets... je gémirai des tiens.

L'écho répètera nos plaintes mutuelles;

L'écho sert les amants malheureux et fidèles.

Le sort, nos ennemis, ne peuvent nous ravir

Le plaisir douloureux de pleurer, de gémir;

Nos larmes sont à nous, nous pouvons les répandre:

Mais Dieux seul, me dis-tu, Dieu seul y doit prétendre.

Cruel! Je t'ai perdu, je perds tout avec toi.

Tout m'arrache des pleurs... tu ne vis plus pour moi.

C'est pour toi... pour toi seul que couleront mes larmes,

Aux pleurs des malheureux Dieu trouve-t-il des charmes? 60

Ecris-moi, je le veux: ce commence enchanteur,

Aimable épanchement de l'esprit et du cœur,

Cet art de converser, sans se voir, sans s'entendre,

Ce muet entretien, si charmant et si tendre,

'art d'écrire, Abailard, fut sans doute inventé

Par l'amante captive et l'amant agité;

Tout vit par la chaleur d'une lettre éloquente,

Le sentiment s'y peint sous les doigts d'une amante.

La primera constatación que evidenciamos es la intensidad de los alejandrinos. Impacta el apasionamiento con el que Eloísa expone sus argumentos. Colardeau ha mantenido la línea argumental, reproduciendo en su versión los pilares semánticos que sustentan esta estrofa: invitación a Abelardo a que le escriba y responda a sus cartas; triste lamento de Eloísa al saberse sola en su dolor; y exaltación a la escritura. Analicemos ahora cómo Eloísa expresa dichos razonamientos.

Los versos 49 al 55 recogen la primera noción. La alocución se inicia con imperativo "écris-mol" que introduce, con el signo ortográfico de dos puntos, una explicación expuesta mediante imperativos: "formons", "partage". Eloísa desea fervientemente que Abelardo le escriba, que retome el contacto, que ella pueda sentir que no está sola sino que de nuevo están unidos y vuelvan a ser dos. Este contacto recuperado reavivará la ilusión y dará sentido a su vida: los lamentos de Eloísa ya no se perderán en el vacío, sino que ahora tendrán un receptor, el mejor de los receptores, su esposo. Ella también se tornará ávida receptora de las desdichas que en sus cartas narre Abelardo, procurándole consuelo y afecto. Estas ideas se sustentan en la continua reiteración de "nosotros", mediante formas 
verbales en primera persona del plural ("formons", "pouvons"), adjetivos posesivos ("nos plaintes", "nos ennemis", "nos larmes"), pronombres personales sujeto y complemento ("nous ravir", "à nous", "nous pouvons"). Los dos amantes unidos en un solo dolor podrán desafiar sin temor a sus crueles enemigos.

En el siguiente grupo de versos (desde el 56 al 60), Colardeau rubrica con su impronta personal: ha cambiado la delicadeza y languidez de los versos de Pope por una expresión mucho más vehemente. En este pasaje, Eloísa no se resigna ni se recrea en su desdicha, sino que eleva su voz en grave tono acusador contra Abelardo y contra el mismo Dios, de ahí que estos versos se orienten a la persona "tú" y no a "nosotros", (pronombres personales sujeto, complemento y pronombres tónicos: "dis-tu", "je t’ai perdu", "avec tol", "tu ne vis plus", "pour tor") y se exponga por tres veces el nombre de Dios (vv. 56, 60). Eloísa recrimina a Abelardo que haya sucumbido, procurando a sus enemigos una grata victoria. Según Abelardo, su desdicha es por voluntad divina "Dieu seul y doit prétendre", así lo ha querido Dios y él se somete. Ante estas palabras, Eloísa reacciona con ira llamándolo "Cruel!", y continúa su relato con la constatación de un hecho: Abelardo ha dejado de amarla y sin él, su vida ya no tiene sentido, de modo que lo único que le queda es sofocar su dolor a través del llanto ("pleurs", "larmes", "pleurs", vv. 58, 59, 60). Esta confirmación viene expresada por la reiteración del verbo "perdre" (v. 57) y del pronombre indefinido "touf" (vv. 57,58 ). La interrogación retórica que cierra este epígrafe ("Aux pleurs des malheureux Dieu trouve-t-il des charmes?" v. 60) deja en el aire una duda atroz: ¿acaso Dios es tan cruel que encuentra regocijo en el dolor de sus hijos?

Los versos de Cobardeau, con los que concluimos el análisis, reproducen el mismo tema que encontramos en el texto original: la apología de la escritura. Colardeau vuelve a iniciar esta serie con la exigencia de Eloísa a Abelardo a que le escriba ("écris-moi"). Ahora no se trata de una invitación, sino de una reclamación. Este cambio de tono se aprecia en la ampliación recogida en el verso 61, "je le veux". A partir de esta expresión, Eloísa realiza una pormenorizada explicación de los beneficios que la escritura puede reportarles, beneficios que vienen detallados por metáforas hábilmente calificadas ("enchanteur", "aimable") que se suceden desde el verso 61 hasta 66. Cada uno de los adjetivos honra una virtud de la escritura. Eloísa también menciona a los amantes anónimos que como ellos sufrieron la distancia "Par l'amante captive et l'amant agité" (v. 66). Los dos últimos versos concluyen a modo de sentencia: "Tout vit par la chaleur d'une lettre éloquente / Le sentiment s'y peint sous les doigts d'une amante". El único anhelo que le queda a Eloísa es poder recibir una carta de su 
Abelardo, "lettre éloquente", que dé sentido a su vida y que, en su respuesta, permita a Eloísa transcribir su locura de amor.

\section{CONCLUSIÓN}

Tal como apuntábamos en la introducción, la correspondencia de Abelardo y Eloísa ha sido tema de críticos y escritores de todos los tiempos. El primero de ellos fue Jean de Meung, primero en aludir a ella en el prefacio de su obra el Roman de la Rose y primero en traducir al francés dicha correspondencia, que ha llegado hasta nosotros por una copia de primeros del siglo XIV conservada en la Biblioteca Nacional de París. En el siglo XV, François Villon, en su obra Le Testament (1461), menciona a célebres mujeres por su belleza e inteligencia entre las que incluye a Eloísa: "Ou est la tres sage Heloïs / Pour qui fut châtré et puis moyne / Pierre Esbaillart a Saint Denis? ${ }^{13 "}$. No obstante hasta el siglo XVII no se publica la primera traducción francesa de las cartas de Eloísa, realizada en 1642 por François de Grenaille ${ }^{14}$, donde incluye cuatro cartas de Eloísa bajo la rúbrica de "lettres chrétiennes". Dichas cartas poseen una cierta unidad y la progresión dramática de una trama y aunque dos de ellas son supuestas (la primera y la cuarta), las dos auténticas se ajustan con bastante fidelidad al texto original. Años más tarde, en el primer cuarto del siglo XVIII, en Inglaterra, Alexander Pope que había iniciado su carrera literaria en 1704 con algunas publicaciones de poesía a imitación de Virgilio, poemas heroicos y alguna obra teórica, decide centrarse en la traducción: traduce así La lliada y La Odisea con las que adquirirá bastante notoriedad, reconocimiento también conseguido por la publicación en 1717 de un libro de poemas que incluye la célebre epístola Eloisa to Abelard. La publicación de esta composición supuso al autor un éxito inmediato. En ella Pope imitaba el género de las epístolas heroicas de Ovidio y basaba su argumento en las cartas de Abelardo y Eloísa traducidas por John Hugues en 1713. En esta etapa de su vida, Pope se sentía atraído por la heroína inteligente, lúcida, enamorada y de extrema sensibilidad como era Eloísa y decide abordar su obra con pasión, de ahí el carácter único de esta obra. Las primeras versiones en francés de la heroida de Pope fueron la de Aimé Ambroise Joseph Feutry (1751), más destacable en forma que en fondo, y la traducción libre de Charles Pierre Colardeau (1758), que conforme a un ideal de libre imitación más que de fiel traducción, el autor concede mucho al gusto francés de la época en ciertas escenas agraciadas y en la seductora musicalidad de los versos que con el calculado artificio de

${ }^{13}$ Euvres poétiques de François Villon, texte établi et annoté par André Mary, Chronologie, préface et indez par Daniel Poirion, Paris, Garnier-Flammarion, 1965, p. 59.

${ }^{14}$ Les Lettres d'Héloïse traduites par François de Grenaille, en Nouveau recueil de lettres de dames tant anciennes que modernes, Paris, R. Quinet, 1642. 
frecuentes particiones, suspensiones y añadidos intentan crear efectos cargados de sugestiones.

Con este trabajo hemos querido dejar constancia que de un modo $u$ otro la historia de Eloísa y Abelardo es universal, pues universales son los temas que en ella se tratan: amor, ilusión, dolor, tragedia; temas con los que se ha nutrido la literatura de todos los tiempos y de todas las nacionalidades. La traducción o la versión, caso de los autores que en este estudio hemos tratado, ha favorecido en gran medida la difusión y reproducción de obras de características singulares que lectores de todas las épocas han podido conocer y con las que han podido disfrutar, al tiempo que ha servido a multitud de grandes escritores al conocimiento de nuevas tendencias y nuevas corrientes procedentes de destinos cercanos o lejanos. Por ello las obras de Pope, Feutry y Colardeau, tan semejantes en esencia y divergentes en forma y estilo, dan muestra de la creatividad de cada autor, de su originalidad, de su inspiración, de las corrientes literarias a las que se acoge, de su destreza versificadora, de su propia época, ofreciendo sus conocimientos y su modo de sentir a generaciones posteriores.

REFERENCIAS BIBLIOGRÁFICAS

ÁlvAREZ JURADO, M.: La expresión de la pasión femenina a través de la epístola amorosa: el modelo portugués, Publicaciones de la Universidad de Córdoba y Obra Social y Cultural Cajasur, Córdoba, 1998.

ChARRIER, $\mathrm{CH}$.: Héloïse dans l'histoire et dans la légende, Champion, Paris, 1933.

García Calderón, A.: "Eloisa to Abelard de Alexander Pope" en Alfinge, Universidad de Córdoba, no 17, 2007, pp. 49-80.

García PeINADO, M.A.: "La Influencia en Francia de la poesía sepulcral inglesa del XVIII" en Hermeneus, Universidad de Valladolid, t. I, 7, 2005, pp. 87-114.

GILSON, E.: Héloïse et Abélard, Vrin, Paris, 1938 (1964).

GREARD, O.: Lettres complètes d'Abailard à Héloïse, Garnier frères, Paris, 1869.

Pernoud, R.: Héloïse et Abélard, Albin Michel, Paris, 1970.

FROLDI, R.: El tema literario de Eloísa y Abelardo y las Heroidas de José Marchena Biblioteca Virtual Miguel de Cervantes, Alicante, 2000. N. sobre edición original: Edición digital a partir de El siglo que llaman ilustrado: homenaje a Francisco Aguilar Piñal, Madrid, C. S. I. C., 1996, pp. 377-390. [En línea].

<http://www.cervantesvirtual.com/servlet/SirveObras.htm\#1> Consultado el 7 de abril de 2010. 
POPE, A.: Eloisa to Abelard, Works, London, 1717. [En línea] <http://www.monadnock.net/poems/eloisa.html> Consultado el 7 de abril de 2010.

SAURA SÁNCHEZ, A.: Las heroidas francesas y su recepción en España. Estudio y Antología. Universidad de Murcia, Servicio de Publicaciones, 2002. [En línea] <http://books.google.es/books>. Consultado el 5 de abril de 2010. 